\title{
Ertugliflozin Compared to Other Anti-hyperglycemic Agents as Monotherapy and Add-on Therapy in Type 2 Diabetes: A Systematic Literature Review and Network Meta-Analysis
}

\author{
Ann M. McNeill • Glenn Davies • Eliza Kruger • Stacey Kowal • \\ Tim Reason · Flavia Ejzykowicz · Hakima Hannachi · Nilo Cater • \\ Euan McLeod
}

Received: September 19, 2018 / Published online: January 28, 2019

(C) The Author(s) 2019

\section{ABSTRACT}

Introduction: Ertugliflozin is a new sodiumglucose co-transporter-2 inhibitor (SGLT2i) for the treatment of type 2 diabetes mellitus. As there are no head-to-head trials comparing the efficacy of SGLT2is, the primary objective of this analysis was to indirectly compare ertugliflozin to other SGLT2i in patient populations with inadequately controlled glycated hemoglobin (HbA1c $>7.0 \%)$ and previously treated with either diet/exercise, metformin alone or metformin plus a dipeptidyl peptidase- 4 inhibitor (DPP4i).

Enhanced Digital Features To view enhanced digital features for this article go to https://doi.org/10.6084/ m9.figshare.7565786.

Electronic supplementary material The online version of this article (https://doi.org/10.1007/s13300019-0566-x) contains supplementary material, which is available to authorized users.

A. M. McNeill ( ()$\cdot$ G. Davies · F. Ejzykowicz ·

H. Hannachi

Merck \& Co., Inc., Kenilworth, NJ, USA

e-mail: annie_mcneill@merck.com

E. Kruger $\cdot$ S. Kowal · T. Reason

IQVIA, Parsippany, NJ, USA

N. Cater

Pfizer, New York, NY, USA

E. McLeod

Pfizer, Tadworth, UK
Methods: A systematic literature review (SLR) identified randomized controlled trials (RCTs) reporting outcomes at 24-26 weeks of treatment. Comparators to ertugliflozin were the SGLT2is canagliflozin, dapagliflozin and empagliflozin, with non-SGLT2i comparators also evaluated third-line [insulin and glucagon-like peptide-1 receptor agonists (GLP-1 RAs)]. Outcomes were change from baseline in HbA1c, weight and systolic blood pressure (SBP) as well as HbA1c $<7 \%$ and key safety events. Bayesian network meta-analysis was used to synthesize evidence. Results are presented as the median of the mean difference (MD) or as odds ratios with 95\% credible intervals (CrI).

Results: In patients uncontrolled on diet/exercise, the efficacy of ertugliflozin $5 \mathrm{mg}$ monotherapy was not significantly different from that of other low-dose SGLT2is in terms of HbA1c reduction, while ertugliflozin $15 \mathrm{mg}$ was more effective than dapagliflozin $10 \mathrm{mg}$ (MD $-0.36 \%$, CrI $-0.65,-0.08)$ and empagliflozin $25 \mathrm{mg}$ (MD - 0.31\%, CrI - 0.58, - 0.04). As add-on therapy to metformin, ertugliflozin $5 \mathrm{mg}$ was more effective in lowering HbA1c than dapagliflozin $5 \mathrm{mg}(\mathrm{MD}-0.22 \%$, CrI $-0.42,-0.02$ ), and ertugliflozin $15 \mathrm{mg}$ was more effective than dapagliflozin $10 \mathrm{mg}$ (MD $-0.26 \%$, CrI $-0.46,-0.06)$ and empagliflozin $25 \mathrm{mg}$ (MD - 0.23\%, CrI - 0.44, - 0.03). Among patients uncontrolled on combination therapy metformin plus a DPP4i, no relevant RCTs with insulin were identified from the SLR. 
One study with a GLP-1 RA was included in a sensitivity analysis due to limited data. There were no differences between ertugliflozin 5 or $15 \mathrm{mg}$ and other SGLT2is, with the exception of dapagliflozin $10 \mathrm{mg}$, which was significantly less effective when added to sitagliptin and metformin. Overall, there were no other significant differences for remaining efficacy and safety outcomes except for a lower SBP for canagliflozin $300 \mathrm{mg}$ compared to ertugliflozin $15 \mathrm{mg}$ in the diet/exercise population.

Conclusions: Indirect comparisons for $\mathrm{HbA1c}$ reduction found that ertugliflozin $5 \mathrm{mg}$ was more effective than dapagliflozin $5 \mathrm{mg}$ when added to metformin monotherapy, whereas ertugliflozin $15 \mathrm{mg}$ was more effective than dapagliflozin $10 \mathrm{mg}$ and empagliflozin $25 \mathrm{mg}$ when added to diet/exercise and to metformin monotherapy. The HbA1c reduction associated with ertugliflozin was no different than that associated with canagliflozin across all populations.

Funding: Merck Sharp \& Dohme Corp., a subsidiary of Merck \& Co., Inc., Kenilworth, NJ, USA, and Pfizer Inc., New York, NY, USA.

Keywords: Canagliflozin; Dapagliflozin; Empagliflozin; Ertugliflozin; Network metaanalysis; SGLT2; Systematic literature review; Type 2 diabetes

\section{INTRODUCTION}

Sodium-glucose co-transporter 2 inhibitors (SGLT2is) are effective in lowering glycated hemoglobin (HbA1c) levels and also have beneficial effects on weight and blood pressure $[1,2]$. These potential benefits have been recognized, as evidenced by the increasing prominence of this class of prescription medicine in the latest clinical practice guidelines [3]. Ertugliflozin is the newest SGLT2i to become available, approved as an adjunct to diet and exercise to improve glycemic control in adult patients with type 2 diabetes mellitus (T2DM), with recent regulatory approvals in the United States (USA) (December 2017), European Union (EU) (March 2018) and elsewhere. Regulatory approval of ertugliflozin was based on multiple phase III trials that found ertugliflozin lowered HbA1c, weight and blood pressure [4-8].

The clinical and safety profile of individual SGLT2is has been investigated in clinical trials in comparison to placebo and other oral antidiabetic drug classes, as mono-therapy and addon therapy among patients with T2DM. The SGLT2i drug class as a whole has been also compared to other anti-diabetic drug classes in research using indirect comparison methodology [9]. However, comparisons within a class of medicines are also of interest to clinical practitioners and health policy decision-makers. Because no head-to-head randomized clinical trials (RCTs) assessing efficacy have been conducted among SGLT2is, indirect comparisons synthesized from network-meta analysis (NMA) can provide alternative evidence of comparative efficacy. NMAs are an extension of pairwise meta-analysis that bring together evidence from RCTs and use common comparators to indirectly make comparisons across multiple treatments either within or outside of a drug class. Although this approach allows for an observational synthesis of prior evidence, careful consideration of RCTs included in an NMA is required to minimize potential bias in observed results due to differences in study characteristics (e.g. quality, baseline patient characteristics, disease severity) that can influence the treatment effects of the interventions [10].

Several indirect comparisons within the SGLT2i class have been published comparing canagliflozin, dapagliflozin and empagliflozin. These have either compared these drugs across all trial populations or focused on patients inadequately controlled on either diet and exercise or metformin $[11,12]$. These comparisons have not included ertugliflozin as data from trials with ertugliflozin were not yet available at the time of the studies.

Thus, the primary objective of the research reported here was to conduct a systemic literature review (SLR) and NMA to assess the efficacy and safety of ertugliflozin relative to other SGLT2is for the treatment of T2DM in three patient populations defined by inadequate control of HbA1c during prior treatments with (1) diet and exercise alone, (2) metformin alone and (3) metformin plus a dipeptidyl peptidase- 4 
inhibitor (DPP4i). Given the established role of insulin and glucagon-like peptide-1 receptor agonists (GLP-1 RAs) as options for third-line therapy, a secondary objective was to include these as comparators in the population uncontrolled on combination therapy with metformin and a DPP4i.

NMAs require that heterogeneity between studies be minimized; therefore, the present analyses focused on each population separately. As there is no published evidence synthesis specifically evaluating SGLT2i performance in those inadequately controlled on combination therapy with metformin plus a DPP4i, a secondary objective was to compare the effectiveness and safety of ertugliflozin added to dual therapy with metformin + sitagliptin (a combination regimen consisting of three oral antihyperglycemic therapies) to the addition of insulin or dual therapy (metformin plus a GLP-1 RA) in this population.

\section{METHODS}

This article is based on previously conducted studies and does not contain any new studies with human participants or animals performed by any of the authors.

\section{Data Sources and Searches}

This study was conducted according to a prespecified protocol and followed the standard guidelines for conducting and reporting SLRs and NMAs [13-15]. PubMed, Embase and Cochrane databases were searched using the Ovid platform through to December 2016 for English-language RCTs reporting outcomes at 24-26 weeks of follow-up [see Electronic Supplementary Material (ESM) for search strategy]. In addition to the primary search strategy, desk research was performed to access relevant gray literature [e.g. National Institute for Clinical Excellence (NICE) technology assessments, clinical treatment guidelines from 2010 to the present, European Public Assessment Reports (EPAR) and Food and Drug Administration label documents] for missing variables and to ensure all relevant trials were identified via the search. See ESM Table 1 for search terms.

\section{Study Selection}

The patient populations, interventions, comparators, outcomes and study design (PICOS) statement are presented in Table 1 . In brief, patients were adults with T2DM, uncontrolled HbA1c (all patients with $\mathrm{HbA} 1 \mathrm{c} \geq 7.0 \%$ ) and either managed with diet and exercise, on metformin alone; or on metformin plus a DPP4i prior to intervention. Studies evaluating treatments in special populations, such as those with renal impairment, were excluded.

Comparators to ertugliflozin $5 \mathrm{mg}$ and $15 \mathrm{mg}$ were other commercially available SGLT2i products in the USA and the EU, including canagliflozin $100 \mathrm{mg}$ and $300 \mathrm{mg}$, dapagliflozin $5 \mathrm{mg}$ and $10 \mathrm{mg}$ and empagliflozin $10 \mathrm{mg}$ and $25 \mathrm{mg}$, and placebo for all populations. For those inadequately controlled on combination therapy with metformin plus a DPP4i, GLP-1 RAs and insulins were also included in the scope of the SLR.

\section{Data Extraction and Quality Assessment}

Two researchers performed the literature search and conducted an initial abstract review. Uncertainty regarding whether to include studies was resolved either through reconciliation or via consultation with a third reviewer. Data extraction forms were developed to capture the RCT evidence, with data extracted for each outcome measure. Data were extracted by one reviewer and checked by a second reviewer for quality assurance and completeness.

To minimize heterogeneity, outcomes were extracted from primary analyses using last observation carried forward (LOCF) where available. Study quality was assessed via the Grades of Recommendation, Assessment, Development and Evaluation (GRADE) working group guidelines [16]. The assessment of study quality was used to determine feasibility of networks and sensitivity analyses. 
Table 1 Patient, population, inteventions, comparators, outcomes and study design (PICOS) statement

\section{Components of PICOS Description statement}

Patient population

Intervention

Comparators

Outcome measures

Study design

Restrictions
T2DM (adults, $18+$ years), uncontrolled HbAlc ( $\mathrm{HbAlc}>7.0 \%)$

Inadequately controlled on diet and exercise:

Ertugliflozin $5 \mathrm{mg}$, ertugliflozin $15 \mathrm{mg}$

Inadequately controlled on metformin alone:

Ertugliflozin $5 \mathrm{mg}+$ metformin, ertugliflozin $15 \mathrm{mg}+$ metformin

Inadequately controlled on metformin + DPP4i:

Ertugliflozin $5 \mathrm{mg}+$ sitagliptin + metformin, ertugliflozin

$15 \mathrm{mg}+$ sitagliptin + metformin

Inadequately controlled on diet and exercise:

SGLT2i (canagliflozin $100 \mathrm{mg} / 300$, dapagliflozin $5 \mathrm{mg} / 10$, empagliflozin $10 \mathrm{mg} / 25$ ), placebo Inadequately controlled metformin alone:

Metformin + SGLT2i (canagliflozin $100 \mathrm{mg} / 300$, dapagliflozin $5 \mathrm{mg} / 10$, empagliflozin $10 \mathrm{mg} / 25)$, metformin + placebo

Inadequately controlled on metformin + DPP4i:

Metformin + DPP4i (saxagliptin, linagliptin, alogliptin, sitagliptin) + SGLT2i (canagliflozin $100 \mathrm{mg} / 300$, dapagliflozin $5 \mathrm{mg} / 10$, empagliflozin $10 \mathrm{mg} / 25$ ) OR placebo

Metformin + DPP $4 \mathrm{i}+$ insulin

Metformin + GLP-1 RA [liraglutide (liraglutide), exenatide, lixisenatide, albiglutide, dulaglutide, semaglutide $]^{\mathrm{a}}$

Continuous outcomes-HbAlc (\%), weight (kg), SBP (mmHg)

Binary outcomes-HbAlc within target range (HbAlc $<7.0 \%)$, NSHE, SHE requiring medical attention, UTIs, GMIs

Randomized controlled trials

Language: English

Publication year: any

Country: any

Trial duration 24-26 weeks, or outcomes reported at 24-26 weeks

DPP4i Dipeptidyl peptidase-4 inhibitor, GLP-1 RA glucagon-like peptide-1 receptor agonist, GMIs genital mycotic infections, HbAlc glycated hemoglobin, NSHE non-severe hypoglycemic event, SBP systolic blood pressure, $S G L T 2 i$ sodium-glucose co-transporter 2 inhibitor, $S H E$ severe hypoglycemic event, UTIs urinary tract infections

a After failure on combination therapy with metformin + DPP4i 


\section{Data Synthesis and Analysis}

The existence of a connected network of studies per outcome as well as study design, patient characteristics and sufficient non-zero frequency of events for safety outcomes was used to assess the feasibility of a valid NMA [17]. Efficacy outcomes included change from baseline in HbA1c, weight, systolic blood pressure (SBP), and proportion of patients with HbA1c of $<7 \%$. Safety outcomes were the incidence of urinary tract infections (UTIs), genital mycotic infections (GMIs), severe and non-severe hypoglycemia events (SHEs, NSHEs) and patients with one or more adverse events (AEs). NMA feasibility analysis was performed on all outcomes. However, due to low frequency of reported events among placebo participants, NMAs were not possible for GMIs and hypoglycemic events in any of the populations of interest.

For remaining outcomes, evidence was synthesized in WinBUGS software [18] using both fixed effect (FE) and random effects (RE) Bayesian NMA models. The FE model was selected unless there was a significant difference in the deviance information criteria (DIC) of $\geq 3$ [19]. The DIC is a measure for how well the model would predict a replicate dataset, as per guidelines. The appropriate statistical models were used based on the nature of the outcomes. An identity link and a normal likelihood were used for continuous outcomes (e.g. HbA1c change from baseline). Logit link with binomial likelihood distribution was used for dichotomous outcomes (e.g. AEs). Non-informative prior distributions of relative treatment effects were used for all outcomes of interest, per published expert guidelines [19].

Results are presented as the median of mean difference (MD) for continuous outcomes and median odds ratio (OR) for binary outcomes. Credible intervals (CrI), analogous to 95\% confidence intervals, were used to determine significance. Bucher tests [20] of inconsistency were performed on all closed loops with direct and indirect evidence for change in $\mathrm{HbA} 1 \mathrm{c}$, weight and SBP to ensure that the results calculated in the NMA (indirect evidence) were consistent with the evidence from RCTs (direct evidence) [21].

\section{Sensitivity Analysis}

Formal meta-regression sensitivity analyses may be used to control for differences in baseline characteristics that may represent effect modifiers of the treatment effect. However, in this research meta-regressions were not feasible for any population due to the insufficient number of studies meeting the inclusion criteria. Therefore, to assess the impact of study heterogeneity on the results, we performed sensitivity analyses for key outcomes (change in HbA1c and weight) for each population.

Two sensitivity analyses were performed for the diet and exercise population. In the first, Kaku [22] was added to the network. This study was excluded initially as the low threshold of HbA1c for inclusion was $6.5 \% \mathrm{HbA} 1 \mathrm{c}$, versus our inclusion criteria of $\geq 7.0 \%$. However, despite potential heterogeneity previous SGLT2i NMAs have included this study, and therefore a sensitivity analysis was considered appropriate $[23,24]$. In the second sensitivity analysis, studies that were not linked to the network via a common comparator (placebo) arm (Hadjadj [25]; Lewin [26]; Rosenstock [27]) were dropped from the network and analyses run. For the uncontrolled on metformin population, one sensitivity analysis was run that excluded studies that were not linked to the network via a placebo arm (VERTIS FACTORIAL randomized trial [28] and DeFronzo [29]).

One sensitivity analysis was conducted for patients inadequately controlled with a combination therapy of metformin plus a DPP4 $i$ that included a GLP-1 RA (liraglutide) [30] for HbA1c and weight change (SBP not reported). Liraglutide was included as a sensitivity analysis as opposed to the base case due to heterogeneity in this study [30]. Specifically, consistent with clinical practice, the liraglutide arm discontinued sitagliptin, resulting in a indirect comparison of triple oral therapy with a SGLT2i with a GLP-1 RA on a background of metformin. Further, a substantial reduction in $\mathrm{HbA1c}$ was observed post-randomization in the placebo 
arm. Compared to other included studies this study was identified as a source of heterogeneity that could confound the analysis and was therefore included in a sensitivity analysis only.

\section{RESULTS}

\section{Systematic Literature Review}

The literature review identified 10,566 non-duplicate titles. After a review of the abstracts, 198 papers were identified for full text review. Ultimately, 18 published studies met the inclusion criteria, with two additional studies extracted for sensitivity analyses (Fig. 1). At the time of the literature search, the results of four ertugliflozin clinical trials (VERTIS MONO, VERTIS MET, VERTIS FACTORIAL, VERTIS SITA2) had not been published. Therefore, SLR results were supplemented with the manufacturer's clinical study reports for the evidence synthesis. The results from the VERTIS MONO, VERTIS MET, VERTIS FACTORIAL and VERTIS SITA2 trials were subsequently published by Terra et al. [8], Rosenstock [7], Pratley [6] and Dagogo-Jack [4], respectively. No additional studies were identified via gray literature searches. Figure 1 displays the Preferred Reporting Items for Systematic Reviews and Meta-Analyses (PRISMA) diagram.

\section{Study Characteristics and Quality Assessment}

Study characteristics for all three populations are described in Table 2, and network diagrams showing feasible comparisons are presented in Fig. 2. Outcome data is available in ESM Table 2. Quality assessment determined that all studies across the three populations were RCTs with clearly described interventions; all were assessed to be of high quality.

\section{Patients Inadequately Controlled on Diet and Exercise}

All included trials were double-blind RCTs $(n=11)$ and all but two were placebo controlled $[26,27]$. Most were multinational studies, and two RCTs involved only an Asian population
$[31,32]$. Mean baseline HbA1c was generally similar, clustering in the range of $7.9-8.3 \%$. However, in two studies the mean baseline HbA1c level was slightly higher, respectively at 8.7 [25] and 8.8\% [27]. Other potential effect modifiers, such as SBP, and patient age were found to be relatively similar across studies, while baseline weight was lower in the studies with an Asian population [31, 32]. Mean baseline estimated glomerular filtration rate (eGFR) varied from a low of $83 \mathrm{~mL} / \mathrm{min} / 1.73 \mathrm{~m}^{2}$ [31] to a high of $93 \mathrm{~mL} / \mathrm{min} / 1.73 \mathrm{~m}^{2}$ [25] for studies included in the base case, with an outlier of $67 \mathrm{~mL} / \mathrm{min} /$ $1.73 \mathrm{~m}^{2}$ for the study included in a pre-specified sensitivity analysis [22]. The percentage of females in each patient population varied from a low of $35 \%[31,32]$ to a high of $56 \%$ [33].

\section{Patients Inadequately Controlled on Metformin Alone}

All trials were double-blind RCTs $(n=7)$, and all but two studies were placebo controlled $[28,29]$. All but one RCT were multinational $(n=6)$, and one comprised exclusively an Asian population [34]. Mean baseline HbA1c was $8.1 \%$, with all studies falling in the range of 7.9 to $8.1 \%$ with the exception of one study $(8.6 \%$; VERTIS FACTORIAL trial, which was removed in sensitivity analysis) [28]. Baseline weight was similar in all studies, with the exception of the study of Yang et al. [34], which had a lower mean baseline weight of $71 \mathrm{~kg}$. Potential effect modifiers (SBP, patient age, percentage female, eGFR) were otherwise found to be relatively similar across studies.

\section{Patients Inadequately Controlled on combination therapy with Metformin Plus a DPP4i}

The combinations identified (plus background therapies containing metformin and a DPP4i) were dapagliflozin $10 \mathrm{mg}$ (metformin + sitagliptin), dapagliflozin $10 \mathrm{mg}$ (metformin + saxagliptin), empagliflozin $10 \mathrm{mg}$ and $25 \mathrm{mg}$ (metformin + linagliptin), titrated canagliflozin (metformin + sitagliptin) and ertugliflozin $5 \mathrm{mg}$ and $15 \mathrm{mg}$ (metformin + sitagliptin). No RCTs that included insulin as a comparator met the inclusion criteria for investigation as add-on to 


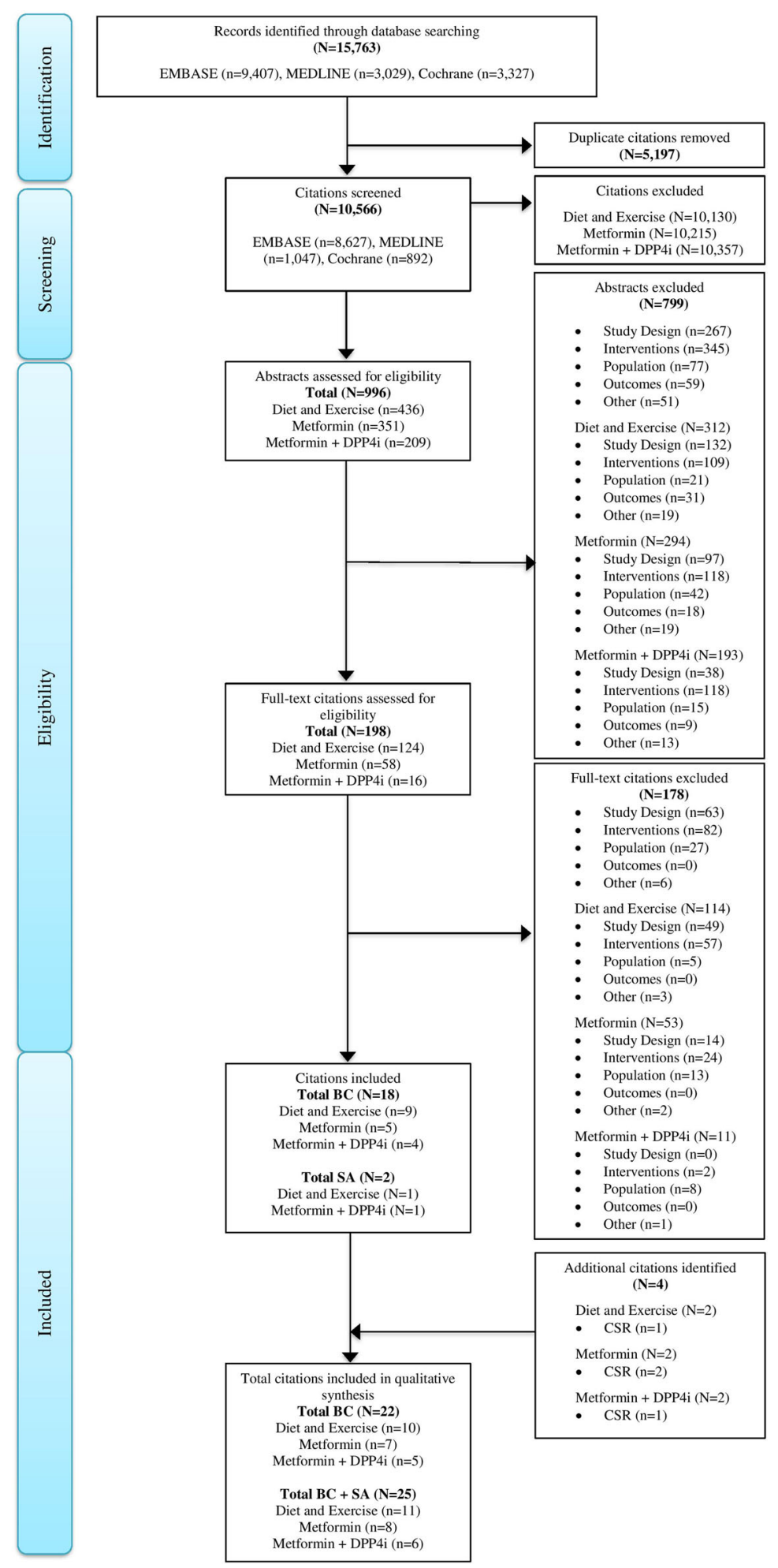

Fig. 1 PRISMA diagram. $B C$ Base case, $C S R$ clinical study report, $D P P 4 i$ dipeptidyl peptidase-4 inhibitor, $S A$ sensitivity analysis, Diet and Exercise inadequately controlled on diet and exercise, Metformin Alone inadequately controlled on metformin alone, Metformin plus DPP4i inadequately controlled on metformin plus a DPP4i 
Table 2 Study design and mean baseline characteristics

\begin{tabular}{|c|c|c|c|c|c|c|}
\hline $\begin{array}{l}\text { First author of } \\
\text { study or name } \\
\text { of trial }\end{array}$ & Interventions & Previous/concurrent treatment & $\begin{array}{l}\text { Study } \\
\text { duration } \\
\text { (weeks) }\end{array}$ & $\begin{array}{l}\text { Number of } \\
\text { participants }\end{array}$ & $\begin{array}{l}\text { Age } \\
\text { (years) }\end{array}$ & $\begin{array}{l}\text { Female } \\
(\%)\end{array}$ \\
\hline \multicolumn{7}{|c|}{ Uncontrolled on diet and exercise regimen } \\
\hline Bailey [42] & DAPA $5 \mathrm{mg}$, PBO & $\begin{array}{l}\text { Treatment naive or having } \\
\text { received ADT for }<24 \text { weeks } \\
\text { since the original diagnosis or } \\
\text { no ADT for }>14 \text { days during } \\
\text { the } 12 \text { weeks prior to } \\
\text { enrolment and no ADT } \\
\text { during the } 4 \text { weeks prior to } \\
\text { enrolment }\end{array}$ & 24 & 136 & 52.4 & 49 \\
\hline Ferrannini $[43]$ & $\begin{array}{l}\text { DAPA } 5 \mathrm{mg}, \text { DAPA } \\
10 \mathrm{mg}, \mathrm{PBO} \\
\text { morning dose }\end{array}$ & Treatment naive & 24 & 209 & 52.0 & 54 \\
\hline Hadjadj [25] & $\begin{array}{l}\text { EMPA } 10 \mathrm{mg} \\
\text { EMPA } 25 \mathrm{mg}\end{array}$ & $\begin{array}{l}\text { Treatment naive or no } \mathrm{ADT} \\
\text { for } \geq 12 \text { weeks prior to } \\
\text { randomization }\end{array}$ & 24 & 299 & 53.2 & 46 \\
\hline Inagaki [31] & $\begin{array}{l}\text { CANA } 100 \mathrm{mg} \text {, } \\
\text { PBO }\end{array}$ & $\begin{array}{l}\text { Treatment naive or washout } \\
\text { period of } \geq 55 \text { days of ADT } \\
\text { before starting run-in period }\end{array}$ & 24 & 183 & 58.3 & 35 \\
\hline $\mathrm{Ji}[32]$ & $\begin{array}{l}\text { DAPA } 5 \mathrm{mg}, \text { DAPA } \\
10 \mathrm{mg}, \mathrm{PBO}\end{array}$ & $\begin{array}{l}\text { Treatment naive or no ADT } \\
\text { for }<24 \text { weeks since original } \\
\text { diagnosis }\end{array}$ & 24 & 393 & 51.4 & 35 \\
\hline Kaku $[22]^{\mathrm{a}}$ & $\begin{array}{l}\text { DAPA } 5 \mathrm{mg}, \text { DAPA } \\
10 \mathrm{mg}, \mathrm{PBO}\end{array}$ & $\begin{array}{l}\text { Treatment naïve or washout } \\
\text { period of } 8 \text { weeks. }\end{array}$ & 24 & 261 & 58.8 & 41 \\
\hline Lewin [26] & $\begin{array}{l}\text { EMPA } 10 \mathrm{mg} \\
\text { EMPA } 25 \mathrm{mg}\end{array}$ & $\begin{array}{l}\text { No } \mathrm{ADT} \geq 12 \text { weeks prior to } \\
\text { randomization }\end{array}$ & 24 & 265 & 55.0 & 47 \\
\hline Roden [44] & $\begin{array}{l}\text { EMPA } 10 \mathrm{mg} \\
\text { EMPA } 25 \mathrm{mg} \\
\text { PBO }\end{array}$ & $\begin{array}{l}\text { No ADT for } 12 \text { weeks prior to } \\
\text { enrolment }\end{array}$ & 24 & 676 & 55.0 & 39 \\
\hline Rosenstock [27] & $\begin{array}{l}\text { CANA } 100 \mathrm{mg}, \\
\text { CANA } 300 \mathrm{mg}\end{array}$ & $\begin{array}{l}\text { Treatment naive or had received } \\
\text { ADT for }<6 \text { months since } \\
\text { diagnosis }\end{array}$ & 26 & 464 & 54.9 & 52 \\
\hline Stenlof [33] & $\begin{array}{l}\text { CANA } 100 \mathrm{mg} \text {, } \\
\text { CANA } 300 \mathrm{mg}, \\
\text { PBO }\end{array}$ & $\begin{array}{l}\text { Treatment naive or } 8 \text {-week } \\
\text { washout of ADT }\end{array}$ & 26 & 584 & 55.4 & 56 \\
\hline $\begin{array}{l}\text { VERTIS } \\
\text { MONO } \\
{[8,45]}\end{array}$ & $\begin{array}{l}\text { ERTU } 5 \mathrm{mg}, \text { ERTU } \\
15 \mathrm{mg}, \mathrm{PBO}\end{array}$ & $\begin{array}{l}\text { Not on an } \mathrm{ADT} \text { for } \geq 8 \text { weeks } \\
\text { or washout of } \geq 8 \text { weeks }\end{array}$ & 26 & 460 & 56.4 & 43 \\
\hline
\end{tabular}


Table 2 continued

\begin{tabular}{|c|c|c|c|c|c|c|}
\hline $\begin{array}{l}\text { First author of } \\
\text { study or name } \\
\text { of trial }\end{array}$ & Interventions & Previous/concurrent treatment & $\begin{array}{l}\text { Study } \\
\text { duration } \\
\text { (weeks) }\end{array}$ & $\begin{array}{l}\text { Number of } \\
\text { participants }\end{array}$ & $\begin{array}{l}\text { Age } \\
\text { (years) }\end{array}$ & $\begin{array}{l}\text { Female } \\
(\%)\end{array}$ \\
\hline \multicolumn{7}{|c|}{ Uncontrolled on metformin alone } \\
\hline Bailey [46] & $\begin{array}{l}\text { DAPA } 5 \mathrm{mg}, \text { DAPA } \\
10 \mathrm{mg}, \mathrm{PBO}\end{array}$ & $\mathrm{MET} \geq 1500$ for $\geq 8$ weeks & 24 & 399 & 53.6 & 46 \\
\hline DeFronzo [29] & $\begin{array}{l}\text { EMPA } 10 \mathrm{mg}, \\
\text { EMPA } 25 \mathrm{mg}\end{array}$ & MET $\geq 1500$ for $\geq 12$ weeks & 24 & 277 & 55.8 & 48 \\
\hline Häring [47] & $\begin{array}{l}\text { EMPA } 10 \mathrm{mg} \\
\text { EMPA } 25 \mathrm{mg} \\
\text { PBO }\end{array}$ & MET $\geq 1500$ for $\geq 12$ weeks & 24 & 637 & 55.7 & 43 \\
\hline $\begin{array}{l}\text { Lavalle- } \\
\text { González [48] }\end{array}$ & $\begin{array}{l}\text { CANA } 100 \mathrm{mg}, \\
\text { CANA } 300 \mathrm{mg} \text {, } \\
\text { PBO }\end{array}$ & $\mathrm{MET} \geq 1500$ for $\geq 8$ weeks & 26 & 906 & 55.4 & 53 \\
\hline Yang $[34]$ & $\begin{array}{l}\text { DAPA } 5 \mathrm{mg}, \mathrm{DAPA} \\
10 \mathrm{mg}, \mathrm{PBO}\end{array}$ & $\mathrm{MET} \geq 1500$ for $\geq 8$ weeks & 24 & 434 & 53.7 & 46 \\
\hline $\begin{array}{l}\text { VERTIS MET } \\
{[7,49]}\end{array}$ & $\begin{array}{c}\text { ERTU } 5 \mathrm{mg}, \text { ERTU } \\
1515 \mathrm{mg}, \mathrm{PBO}\end{array}$ & $\mathrm{MET} \geq 1500$ for $\geq 8$ weeks & 26 & 620 & 56.7 & 54 \\
\hline $\begin{array}{l}\text { VERTIS } \\
\text { FACTORIAL } \\
{[6,28]}\end{array}$ & $\begin{array}{l}\text { ERTU } 5 \mathrm{mg}, \text { ERTU } \\
15 \mathrm{mg}\end{array}$ & $\mathrm{MET} \geq 1500$ for $\geq 8$ weeks & 26 & 498 & 55.2 & 48 \\
\hline \multicolumn{7}{|c|}{ Uncontrolled on combination therapy of metformin plus a DPP $4 \mathrm{i}$} \\
\hline Bailey $[30]^{\mathrm{a}}$ & $\begin{array}{l}\text { LIRA, } \\
\text { PBO + SITA, }\end{array}$ & $\begin{array}{l}\text { SITA } 100 \mathrm{mg} \text { and } \\
\text { MET } \geq 1500 \text { or maximum } \\
\text { tolerated dose } \geq 1000 \mathrm{mg} \text { for } \\
\text { at least } 90 \text { days }\end{array}$ & 26 & 406 & 56.4 & 41 \\
\hline Jabbour $[50]$ & $\begin{array}{l}\text { DAPA } \\
10 \mathrm{mg}+\text { SITA, } \\
\text { PBO + SITA }\end{array}$ & $\begin{array}{l}\text { MET } \geq 1500 \text { and } 10 \text { week } \\
\text { dose-stabilization of SITA } \\
100 \mathrm{mg} .52 \text { of patients were on } \\
\text { MET + SITA } 100 \mathrm{mg} \text { prior } \\
\text { to study commencement }\end{array}$ & 24 & 226 & 56.7 & 41 \\
\hline Mathieu [51] & $\begin{array}{l}\text { DAPA } \\
10 \mathrm{mg}+\text { SAXA } \\
\text { PBO + SAXA }\end{array}$ & $\begin{array}{l}\text { MET } \geq 1500 \text { for } \geq 8 \text { weeks or } \\
\text { MET } \geq 1500 \text { and } \\
\text { DPP4i } \geq 8 \text { weeks }\end{array}$ & 24 & 320 & 55.1 & 54 \\
\hline Rodbard [35] & $\begin{array}{l}\text { CANA } 100 \mathrm{mg} / \\
300 \mathrm{mg}^{\mathrm{b}}+\text { SITA, } \\
\text { PBO + SITA }\end{array}$ & $\begin{array}{l}\text { Met } \geq 1500 \text { and SITA } 100 \mathrm{mg} \\
\quad \text { for } \geq 12 \text { weeks }\end{array}$ & 26 & 213 & 57.4 & 43 \\
\hline
\end{tabular}


Table 2 continued

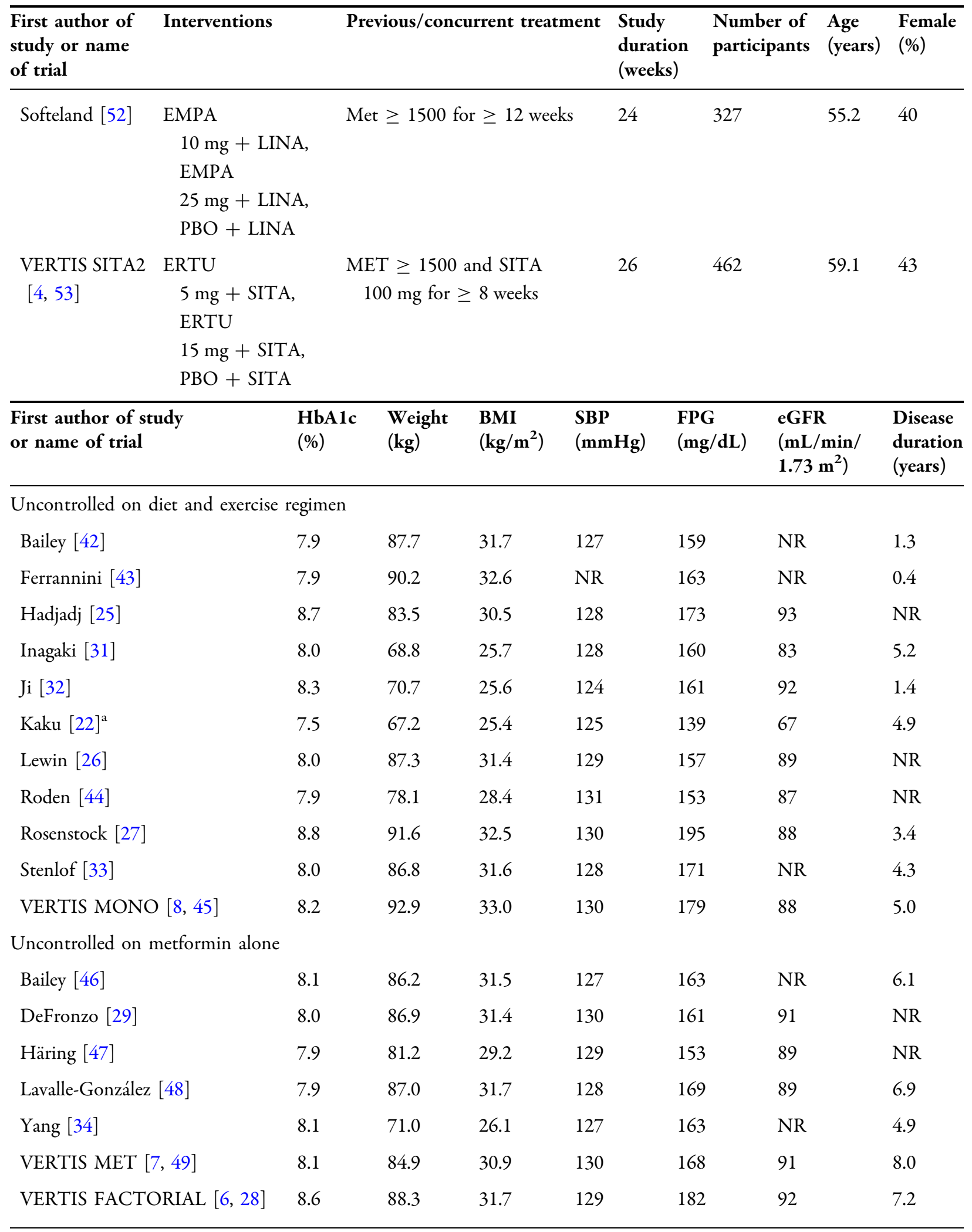


Table 2 continued

\begin{tabular}{|c|c|c|c|c|c|c|c|}
\hline $\begin{array}{l}\text { First author of study } \\
\text { or name of trial }\end{array}$ & $\begin{array}{l}\text { HbAlc } \\
(\%)\end{array}$ & $\begin{array}{l}\text { Weight } \\
(\mathbf{k g})\end{array}$ & $\begin{array}{l}\text { BMI } \\
\left(\mathbf{k g} / \mathrm{m}^{2}\right)\end{array}$ & $\begin{array}{l}\text { SBP } \\
(\mathrm{mmHg})\end{array}$ & $\begin{array}{l}\text { FPG } \\
(\mathrm{mg} / \mathrm{dL})\end{array}$ & $\begin{array}{l}\text { eGFR } \\
(\mathrm{mL} / \mathrm{min} / \\
\left.1.73 \mathrm{~m}^{2}\right)\end{array}$ & $\begin{array}{l}\text { Disease } \\
\text { duration } \\
\text { (years) }\end{array}$ \\
\hline \multicolumn{8}{|c|}{ Uncontrolled on combination therapy of metformin plus a DPP4i } \\
\hline Bailey $[30]^{\mathrm{a}}$ & 8.3 & 90.1 & 32.0 & 131 & 178 & NR & 7.8 \\
\hline Jabbour $[50]$ & 7.9 & 94.1 & NR & NR & 166 & NR & 6.6 \\
\hline Mathieu $[51]$ & 8.2 & 87.0 & 31.7 & NR & 178 & 93 & 7.6 \\
\hline Rodbard [35] & 8.5 & 92.1 & 32.0 & NR & 183 & 91 & 9.9 \\
\hline Softeland [52] & 8.0 & 85.0 & 30.2 & 131 & 167 & 92 & NR \\
\hline VERTIS SITA2 $[4,53]$ & 8.0 & 86.9 & 30.8 & 131 & 170 & 88 & 9.5 \\
\hline \multicolumn{8}{|c|}{$\begin{array}{l}A D T \text { anti-diabetic therapy, } B M I \text { body mass index, } C A N A \text { canagliflozin, } D A P A \text { dapagliflozin, } E M P A \text { empagliflozin, } E R T U \\
\text { ertugliflozin, } e G F R \text { estimated glomerular filtration rate, } F P G \text { fasting plasma glucose, } L I N A \text { linagliptin, } L I R A \text { liraglutide, } \\
M E T \text { metformin, NR not reported, } P B O \text { placebo, } S A X A \text { saxagliptin, } S I T A \text { sitagliptin } \\
\text { a Included in sensitivity analyses only } \\
\text { b CANA dose titrated from } 100 \text { to } 300 \mathrm{mg} \text { for the majority of patients }(85.4 \%)\end{array}$} \\
\hline
\end{tabular}

combination therapy with metformin plus a DPP4i. Only one RCT of a GLP-1 RA (liraglutide on background of metformin) met the inclusion criteria; as such, this study was included in a sensitivity analysis to explore the NMA's secondary objective. All included trials were placebo-controlled double-blind RCTs. Limited variability was observed in the baseline characteristics of the included studies.

Given the limited number of studies meeting the inclusion criteria of our study, it is important to note the elements of heterogeneity in study designs that should be considered when interpreting the findings. In addition to metformin, study participants had differing DPP4i background therapies, requiring an assumption of a non-differential impact of underlying DPP4i therapy. Further, in the study of Rodbard et al. [35] the patients underwent dose titration of canagliflozin $(84.5 \%$ titrated from 100 to $300 \mathrm{mg}$ ), complicating the ability of the authors to interpret a distinct low or distinct high dose. Finally, patients randomized into the liraglutide arm in the study of Bailey et al. [30] (included in sensitivity analysis 1) discontinued sitagliptin and commenced liraglutide with weekly dose escalation until the maintenance dose of $1.8 \mathrm{mg} /$ day was reached.

\section{Network Meta-analysis}

The forest plots for key efficacy outcomes of HbA1c, weight loss and SBP for ertugliflozin compared to the respective low and high doses for other SGLT2i for each population are shown in Fig. 3. At the international level there is some variability in the starting dose or availability of specific SGLT2i doses. Therefore, we provide supplementary results that include additional dose comparisons as well as outcomes not shown in this article (ESM Tables 3,4). Note that differences between treatments with credible intervals overlapping zero (for median of $\mathrm{MD}$ ) or one (for median OR) were not considered to be significant.

\section{Inadequately Controlled on Diet and Exercise} For the population on diet and exercise, FE models were selected for all analyses. Ertugliflozin $15 \mathrm{mg}$ was significantly more effective in reducing HbA1c level than either dapagliflozin $10 \mathrm{mg}$ (MD - 0.36\%; CrI - 0.65, - 0.08) or 
empagliflozin $25 \mathrm{mg}(\mathrm{MD}-0.31 \%$; CrI - 0.58, $-0.04)$. There were no significant differences between ertugliflozin $5 \mathrm{mg}$ and dapagliflozin $10 \mathrm{mg}$ in the base case (MD - 0.19; CrI - 0.48; 0.09) (ESM Table 3). At high doses only, canagliflozin was significantly more effective than ertugliflozin in reducing SBP. There were no significant differences between SGLT2is for other efficacy outcomes (weight loss, HbA1c below target) for low and high SGLT2i doses, respectively, and there were no significant differences among SGLT2is for safety outcomes (AEs and UTIs). Finally, there was no evidence of inconsistency in the examined outcomes (i.e., direct evidence from the RCTs and indirect results from the NMA did not differ significantly).

Addition of the study of Kaku et al. [22] (i.e. lower HbA1c threshold study) to the sensitivity analyses resulted in ertugliflozin $5 \mathrm{mg}$ becoming significantly more effective than dapagliflozin $5 \mathrm{mg}$ (MD - 0.41\%; CrI - 0.67, - 0.15) and dapagliflozin $10 \mathrm{mg}(\mathrm{MD}-0.38 ; \mathrm{CrI}$ $-0.64,-0.11)$ for HbA1c change, while ertugliflozin $15 \mathrm{mg}$ remained more effective than dapagliflozin $10 \mathrm{mg}$ and empagliflozin $25 \mathrm{mg}$. There were no other changes to the findings between ertugliflozin and other respective low and high doses of other SGLT2is for remaining HbA1c change and weight comparisons. The second sensitivity analysis (dropping studies not connected by placebo [25-27]) did not impact base case findings for ertugliflozin $5 \mathrm{mg}$ and ertugliflozin $15 \mathrm{mg}$ for HbA1c and weight, with the significance for dapagliflozin $10 \mathrm{mg}$ and empagliflozin $25 \mathrm{mg}$ remaining for HbA1c change (ESM Table 5).

\section{Inadequately Controlled on Metformin Alone}

The FE model was selected for all analyses except for weight change. Ertugliflozin was significantly more effective in reducing HbA1c than low and high doses, respectively, of dapagliflozin (ertugliflozin $5 \mathrm{mg}$ vs. dapagliflozin 5 mg MD - 0.22\%; CrI - 0.42, - 0.02). Further, ertugliflozin $15 \mathrm{mg}$ was more effective than dapagliflozin $10 \mathrm{mg}(\mathrm{MD}-0.26 \%$; CrI -0.46 ,
- 0.06) and empagliflozin $25 \mathrm{mg}$ (MD - 0.23\%; CrI $-0.44,-0.03)$. Consistent with the population inadequately controlled on diet and exercise, there were no significant differences between low-dose ertugliflozin $5 \mathrm{mg}$ and highdose dapagliflozin $10 \mathrm{mg}$ on the background of metformin (MD - 0.14\%; CrI - 0.34; 0.06) (ESM Table 3). There were no additional significant differences for other efficacy outcomes (e.g. weight loss and SBP) and safety outcomes (AEs, UTIs). Similar to the population inadequately controlled on diet and exercise, in this population there was again no evidence of inconsistency in examined outcomes (i.e. direct evidence from the RCTs and indirect results from the NMA did not differ significantly).

In the sensitivity analysis, when studies not connected to the network via a placebo arm (VERTIS FACTORIAL trial [6]; Defronzo [29]) were dropped, ertugliflozin $5 \mathrm{mg}$ was no longer significantly more effective than dapagliflozin $5 \mathrm{mg}$ for change in HbA1c due to the slight widening of the credible interval (MD $-0.19 \%$; CrI $-0.40,0.02$ ) while ertugliflozin $15 \mathrm{mg}$ remained significantly more effective than empagliflozin $25 \mathrm{mg}$ and dapagliflozin $10 \mathrm{mg}$, respectively. These sensitivity analyses did not otherwise significantly impact other SGLT2i comparisons for weight and HbA1c change (ESM Table 6).

\section{Inadequately Controlled on Metformin Plus a DPP4i}

Among patients inadequately controlled on combination therapy with metformin plus a DPP4i, FE models were selected for all analyses. All ertugliflozin and also other SGLT2i combinations were significantly more effective than dapagliflozin $10 \mathrm{mg}$ added to metformin + sitagliptin. There were no further significant differences for other efficacy outcomes (e.g. weight loss, SBP, HbA1c below target) between ertugliflozin and low and high SGLT2i doses, respectively. Analyses of AEs and UTIs did not identify any significant differences.

Sensitivity analysis including liraglutide [30] for change in HbA1c did not identify any significant differences between liraglutide and 

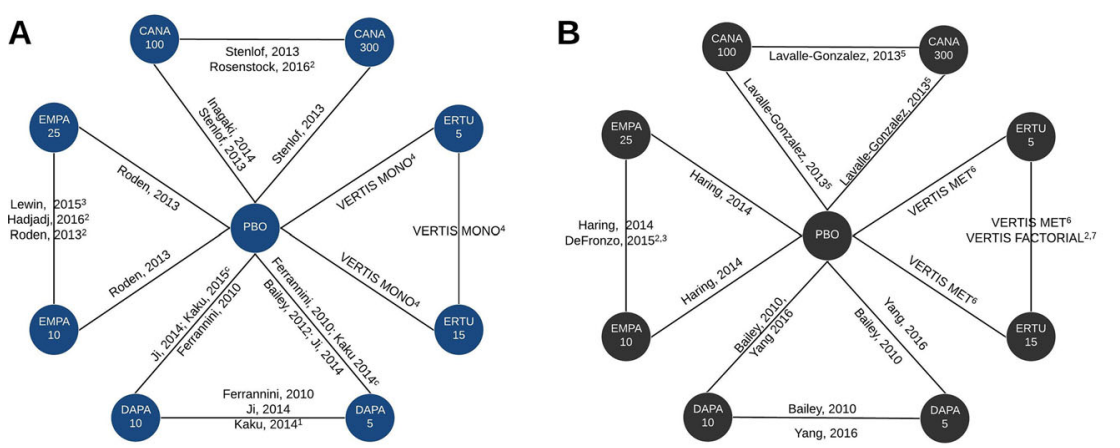

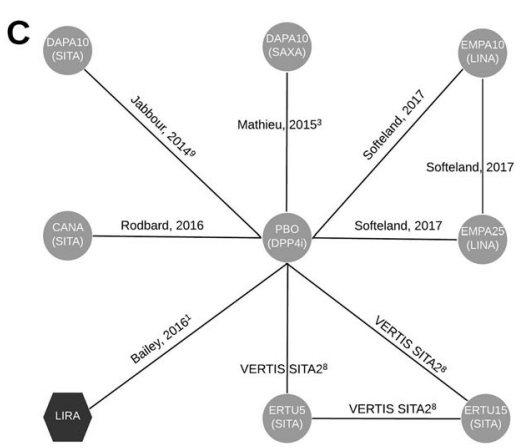

Fig. 2 Network diagrams for type 2 diabetes mellitus (T2DM) patients inadequately controlled on diet and exercise (a), inadequately controlled on metformin alone (b) and inadequately controlled on combination therapy with metformin (MET) plus a dipeptidyl peptidase-4 inhibitor (DPP4i; name listed where relevant) (c). Superscripts: 1 Study added for sensitivity analysis only, 2 study dropped from sensitivity analysis (no connection via placebo), 3 study does not report systolic blood pressure, 4 data from VERTIS MONO, subsequently published by Terra et al. 2017 [8], 5 study does not report non-severe hypoglycemic events, genital mycotic infections (GMIs), severe hypoglycemic events, 6 data from the VERTIS MET trial, subsequently published in Rosenstock et al. 2018 [7],

ertugliflozin treatments (ertugliflozin $5 \mathrm{mg}$ MD $-0.07 \%$; CrI $-0.35,0.22$; ertugliflozin $15 \mathrm{mg}$ $\mathrm{MD}-0.15 \%$; CrI - 0.43, 0.14).

\section{DISCUSSION}

This evidence synthesis represents the first published NMA that compares the effectiveness and safety of ertugliflozin to other SGLT2is. Previous NMAs of the SGLT2i class conducted prior to the availability of ertugliflozin suggested differences in effectiveness, generally favoring canagliflozin [11, 23, 24].

The current analysis has several findings that may be informative to prescribers and healthcare policy-makers. Indirect comparisons for HbA1c reduction found that ertugliflozin $5 \mathrm{mg}$ was associated with greater reductions in HbA1c than dapagliflozin $5 \mathrm{mg}$ in patients uncontrolled on metformin alone, whereas ertugliflozin $15 \mathrm{mg}$ was associated with greater HbA1c reductions compared to dapagliflozin $10 \mathrm{mg}$ and empagliflozin $25 \mathrm{mg}$ when added to the
7 data from the VERTIS FACTORIAL trial, subsequently published in Pratley et al. 2018 [6], 8 data from VERTIS SITA2 trial, subsequently published in Dagogo-Jack et al. 2018 [4], 9 study does not report target glycated hemoglobin, GMIs, urinary tract infections, hypoglycemic events, adverse events. Circles represent sodium-glucose cotransporter-2 inhibitor treatments, hexagons represent glucagon-like peptide-1 receptor agonists. Dark gray shapes are on a background of MET, light grey shapes are on a background combination therapy of MET plus a DPP4i (specific DPP4i stated for clarity). CANA Canagliflozin, $D A P A$ dapagliflozin, EMPA empagliflozin, ERTU ertugliflozin, $L I N A$ linagliptin, $L I R A$ liraglutide, $P B O$ placebo, $S A X A$ saxagliptin, SITA sitagliptin

diet and exercise regimen and to the metformin regimen. HbA1c reduction associated with both doses of ertugliflozin were no different from that with the respective canagliflozin doses across all populations.

In this first study to compare SGLT2is as addon to patients inadequately controlled on combination therapy with metformin plus a DPP4i, the results indicate that both ertugliflozin $5 \mathrm{mg}$ and $15 \mathrm{mg}$ were more effective in lowering HbA1c than dapagliflozin $10 \mathrm{mg}$ when added to a combination of sitagliptin + metformin. However, no significant differences were observed for the comparisons of ertugliflozin (5 mg or $15 \mathrm{mg}$ ) added to sitagliptin + metformin versus dapagliflozin $10 \mathrm{mg}$ added to saxagliptin + metformin.

With the exception of a lower SBP for canagliflozin $300 \mathrm{mg}$ in patients inadequately controlled with diet and exercise, ertugliflozin doses did not differ significantly from other respective low and high doses of other SGLT2is for the remaining outcomes across each 


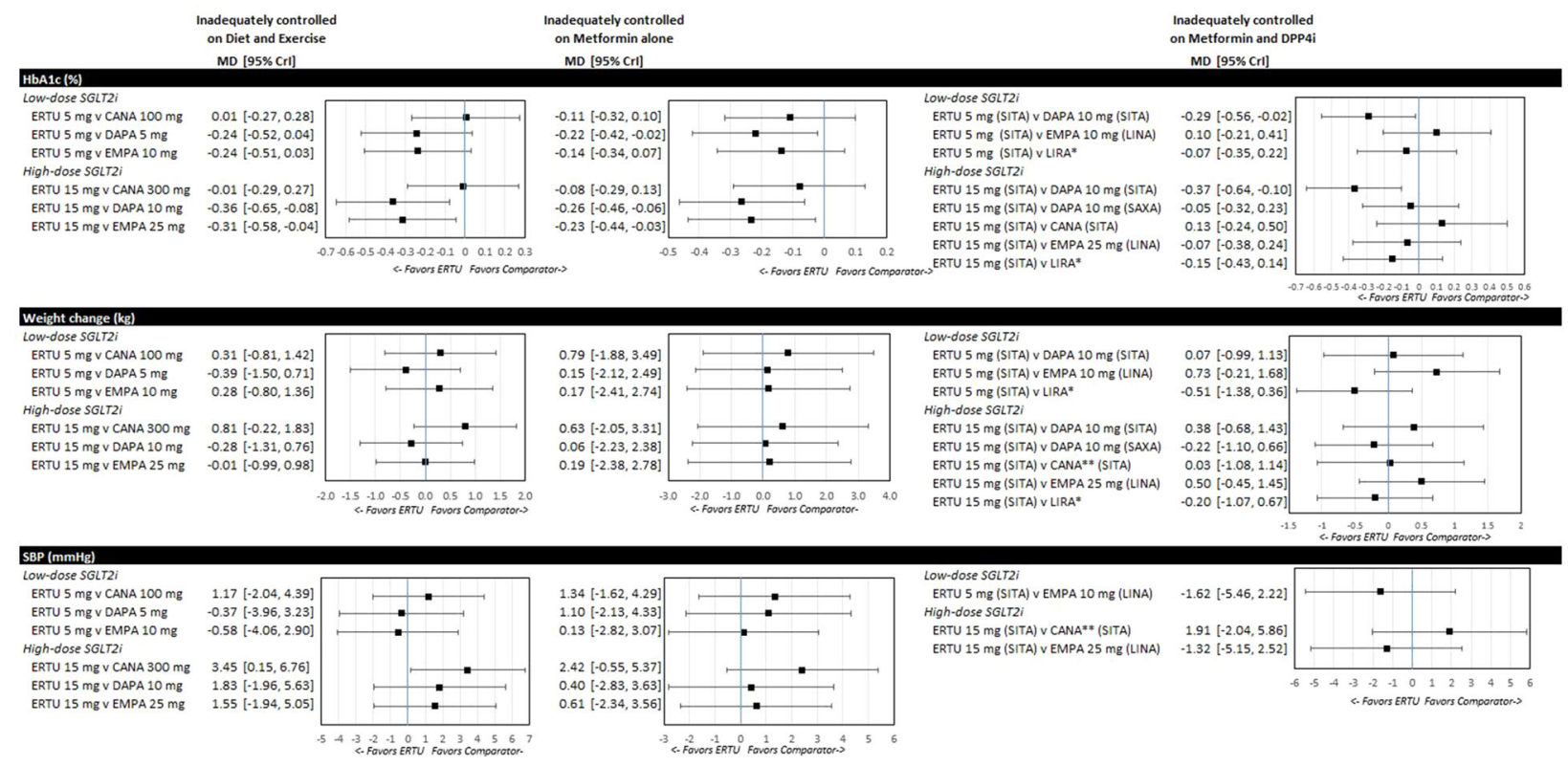

Fig. 3 Forest plots for T2DM patients inadequately controlled on diet and exercise, inadequately controlled on metformin alone and inadequately controlled on combination therapy of metformin plus a DPP4i. CrI
Credible interval, $H b A 1 c$ glycated hemoglobin, $M D$ mean difference. DPP4i in parentheses for clarity, single asterisk indicates results from sensitivity analysis (switch from SITA), double asterisk indicates titrated CANA population. In a sensitivity analysis among patients uncontrolled on combination therapy with metformin plus a DPP4i, no significant differences for efficacy outcomes were found between adding ertugliflozin to the regimen compared to a switch from sitagliptin to liraglutide.

Lastly, as dapagliflozin $5 \mathrm{mg}$ is not universally approved as the starting dose worldwide, comparisons between ertugliflozin $5 \mathrm{mg}$ and dapagliflozin $10 \mathrm{mg}$ are relevant to healthcare decision-makers in those countries. In terms of HbA1c reduction, ertugliflozin $5 \mathrm{mg}$ was no different than the highest available dose of dapagliflozin in patients inadequately controlled by either diet and exercise or by therapy with metformin alone, but it was associated with significantly greater reductions in $\mathrm{HbA1c}$ among patients inadequately controlled on combination therapy with metformin + sitagliptin.

A sound explanation for these differences in efficacy between SGLT2is is not readily apparent in the literature. In the past, differences in selectivity for the SGLT2 receptor have been postulated [23]. However, within this drug class ertugliflozin is one of the most selective approved agents and canagliflozin is the least selective approved agent, but they were among the most effective in terms of HbA1c reduction. Another potential consideration for differences between some SGLT2is is dose selection during clinical development. For example, while dose-response modeling for ertugliflozin indicated that doses at both 5 and $15 \mathrm{mg}$ achieved near maximal urinary glucose excretion (UGE) [36], dapagliflozin doses higher than $10 \mathrm{mg}$ were not selected for phase III trials despite achieving greater UGE (EPAR for Forxiga [37]). Given the lack of definitive explanations for the differences in HbA1c lowering among the individual SGLT2is in this NMA, additional clinical investigations exploring possible mechanistic differences across the SGLT2i class may help address this question.

Interpretation of the results and their significance should consider that NMAs are not equivalent to head-to-head trial evidence, thus 
the role of chance cannot be discounted in explaining some or all of these findings. NMA methods have a number of inherent limitations. First, the analysis is observational in nature since patients can be randomized 'within' but not 'between' trials. Second, despite searching secondary sources, such as labels, not all outcomes were available across all trials, which resulted in exclusion of some comparators for affected outcomes. In addition, evidence synthesis outcomes for GMIs, NSHE and SHE could not be interpreted due to the scarcity of events that prevented network convergence (i.e. unstable results prevented robust comparisons). Nevertheless, visual inspection of the results indicates that these outcomes were similar across clinical trials and active interventions. Third, between-study heterogeneity may have been present. For example, relatively small differences in potential effect modifiers, such as mean baseline HbA1c, existed between studies in the data synthesis and could have influenced study findings. However, the observed consistency of results from the base case and sensitivity analyses that suggest additional HbA1c lowering with ertugliflozin versus dapagliflozin and empagliflozin, in both mono- and dual-therapy populations, makes this explanation less likely.

In addition, regarding the population inadequately controlled on metformin plus a DPP4i, where a mix of DPP4is were used in the background therapy (sitagliptin, saxagliptin and linagliptin) in combination with metformin. By including combinations with different underlying DPP4i regimens, the networks assume that the impact of each placebo + DPP4i combination is comparable. Due to the limited number of studies identified for this population the impact of this assumption on results could not be evaluated. Similarly, switching sitagliptin to liraglutide (consistent with clinical practice) as opposed to adding liraglutide to sitagliptin gave rise to a comparison of a regimen consisting of three oral anti-hyperglycemic agents (ertugliflozin added on to metformin + sitagliptin) versus a dual-therapy regimen with subcutaneous injection (liraglutide added on to metformin) in the sensitivity analysis. Fourth, although the overall quality of included studies was high, relatively few studies met the strict inclusion criteria. The use of strict inclusion and exclusion criteria for RCTs helped to minimize heterogeneity from baseline characteristics. However, minor differences in baseline characteristics (such as HbA1c) need to be recognized, and thus residual confounding cannot be ruled out as a source of bias. Unfortunately, a formal approach of using meta-regression to control for differences in baseline characteristics was not possible due to the small number of studies. Despite these limitations, conducting a SLR and following best practice guidance [13-15] ensured that the findings of this NMA are relevant for healthcare decision-making.

\section{CONCLUSION}

In summary, the current NMA found that ertugliflozin may be more effective in lowering HbA1c than dapagliflozin and empagliflozin in patients uncontrolled on diet and exercise as well as those on therapy with metformin alone. The analysis did not find differences in the HbA1c reductions associated with ertugliflozin compared to canagliflozin across all populations evaluated. The degree to which the efficacy and safety found in short-term studies translate to effects on long-term complications of T2DM, most notably cardiovascular and renal events, is of considerable interest. Completed studies for empagliflozin [38], canagliflozin [39] and dapagliflozin [40] have shown reductions in cardiovascular outcomes. VERTIS CV, an ongoing outcomes trial, will evaluate the effects of ertugliflozin versus standard of care for cardiovascular and renal outcomes [41].

\section{ACKNOWLEDGEMENTS}

We would like to thank Katharine Coyle for assistance provided conducting the systematic literature review.

Funding. Sponsorship for this study and article processing charges were funded by Merck Sharp \& Dohme Corp., a subsidiary of Merck \& Co., Inc. (Kenilworth, NJ, USA) and Pfizer Inc. 
(New York, NY, USA). All authors had full access to all of the data in this study and take complete responsibility for the integrity of the data and accuracy of the data analysis.

Authorship. All named authors meet the International Committee of Medical Journal Editors (ICMJE) criteria for authorship for this article, take responsibility for the integrity of the work as a whole, and have given their approval for this version to be published.

Disclosures. Ann Marie McNeill is an employee and shareholder of Merck Sharp \& Dohme Corp., a subsidiary of Merck \& Co., Inc.. Glenn Davies is an employee and shareholder of Merck Sharp \& Dohme Corp., a subsidiary of Merck \& Co. Flavia Ejzykowicz is an employee and shareholder of Merck Sharp \& Dohme Corp., a subsidiary of Merck \& Co.. Hakima Hannachi is an employee and shareholder of Merck Sharp \& Dohme Corp., a subsidiary of Merck \& Co., Inc.. Euan McLeod is an employee and shareholder of Pfizer Inc. Nilo Cater is an employee and shareholder of Pfizer Inc. Eliza Kruger, Stacey Kowal and Tim Reason declare they have no conflict of interest.

Compliance with Ethics Guidelines. This article is based on previously conducted studies and does not contain any studies with human participants or animals performed by any of the authors.

Data Availability. Data sharing is not applicable to this article as this study was based on published trials which are included in the electronic supplementary material and no datasets were generated during the current study.

Open Access. This article is distributed under the terms of the Creative Commons Attribution-NonCommercial 4.0 International License (http://creativecommons.org/licenses/ by-nc/4.0/), which permits any noncommercial use, distribution, and reproduction in any medium, provided you give appropriate credit to the original author(s) and the source, provide a link to the Creative Commons license, and indicate if changes were made.

\section{REFERENCES}

1. Hasan FM, Alsahli M, Gerich JE. SGLT2 inhibitors in the treatment of type 2 diabetes. Diabetes Res Clin Pract. 2014;104(3):297-322.

2. Scheen AJ. Pharmacodynamics, efficacy and safety of sodium-glucose co-transporter type 2 (SGLT2) inhibitors for the treatment of type 2 diabetes mellitus. Drugs. 2015;75(1):33-59.

3. American Diabetes Association. Standards of medical care in diabetes-2018. Diabetes Care. 2018;41[Suppl 1]:S1-2.

4. Dagogo-Jack S, Liu J, Eldor R, et al. Efficacy and safety of the addition of ertugliflozin in patients with type 2 diabetes mellitus inadequately controlled with metformin and sitagliptin: The VERTIS SITA2 placebo-controlled randomized study. Diabetes Obes Metab. 2017;20(3):530-40.

5. Hollander P, Liu J, Hill J, et al. Ertugliflozin compared with glimepiride in patients with type 2 diabetes mellitus inadequately controlled on metformin: the VERTIS SU randomized study. Diabetes Ther. 2018;9(1):193-207.

6. Pratley RE, Eldor R, Raji A, et al. Ertugliflozin plus sitagliptin versus either individual agent over 52 weeks in patients with type 2 diabetes mellitus inadequately controlled with metformin: The VERTIS FACTORIAL randomized trial. Diabetes Obes Metab. 2018;20(5):1111-20.

7. Rosenstock J, Frias J, Páll D, et al. Effect of ertugliflozin on glucose control, body weight, blood pressure and bone density in type 2 diabetes mellitus inadequately controlled on metformin monotherapy (VERTIS MET). Diabetes Obes Metab. 2018;20(3):520-9.

8. Terra SG, Focht K, Davies M, et al. Phase III, efficacy and safety study of ertugliflozin monotherapy in people with type 2 diabetes mellitus inadequately controlled with diet and exercise alone. Diabetes Obes Metab. 2017;19(5):721-8.

9. Qian D, Zhang T, Zheng P, et al. Comparison of oral antidiabetic drugs as add-on treatments in patients with type 2 diabetes uncontrolled on metformin: a network meta-analysis. Diabetes Ther. 2018;9(5): 1945-48. 
10. Tonin FS, Rotta I, Mendes AM, Pontarolo R. Network meta-analysis: a technique to gather evidence from direct and indirect comparisons. Pharm Pract (Granada). 2017;15(1):943.

11. Shyangdan DS, Uthman OA, Waugh N. SGLT-2 receptor inhibitors for treating patients with type 2 diabetes mellitus: a systematic review and network meta-analysis. BMJ Open. 2016;6(2):e009417.

12. Mearns ES, Sobieraj DM, White CM, et al. Comparative efficacy and safety of antidiabetic drug regimens added to metformin monotherapy in patients with type 2 diabetes: a network metaanalysis. PLoS One. 2015;10(4):e0125879.

13. Hoaglin DC, Hawkins N, Jansen JP, et al. Conducting indirect-treatment-comparison and network-meta-analysis studies: report of the ISPOR task force on indirect treatment comparisons good research practices: part 2. Value Health. 2011;14(4):429-37.

14. Higgins J, Green S. Cochrane handbook for systematic reviews of interventions. Version 5.1. The Cochrane Collaboration. 2015; https://training. cochrane.org/handbook. Accessed 5 Nov 2018.

15. Jansen JP, Fleurence R, Devine B, et al. Interpreting indirect treatment comparisons and network metaanalysis for health-care decision making: report of the ISPOR task force on indirect treatment comparisons good research practices: part 1. Value Health. 2011;14(4):417-28.

16. Tacconelli E. Systematic reviews: CRD's guidance for undertaking reviews in health care. Lancet Infect Dis. 2010;10(4):226.

17. Cope S, Zhang J, Saletan S, Smiechowski B, Jansen JP, Schmid P. A process for assessing the feasibility of a network meta-analysis: a case study of everolimus in combination with hormonal therapy versus chemotherapy for advanced breast cancer. BMC Med. 2014;12(1):93.

18. Lunn DJ, Thomas A, Best N, Spiegelhalter D. WinBUGS-a Bayesian modelling framework: concepts, structure, and extensibility. Stat Comput. 2000;10(4):325-37.

19. Dias S, Sutton AJ, Ades A, Welton NJ. Evidence synthesis for decision making 2: a generalized linear modeling framework for pairwise and network meta-analysis of randomized controlled trials. Med Decis Making. 2013;33(5):607-17.

20. Bucher HC, Guyatt GH, Griffith LE, Walter SD. The results of direct and indirect treatment comparisons in meta-analysis of randomized controlled trials. J Clin Epidemiol. 1997;50(6):683-91.
21. Higgins J, Jackson D, Barrett J, Lu G, Ades A, White I. Consistency and inconsistency in network metaanalysis: concepts and models for multi-arm studies. Res Synth Methods. 2012;3(2):98-110.

22. Kaku K, Kiyosue A, Inoue S, et al. Efficacy and safety of dapagliflozin monotherapy in Japanese patients with type 2 diabetes inadequately controlled by diet and exercise. Diabetes Obes Metab. 2014;16(11):1102-10.

23. Zaccardi F, Webb D, Htike Z, Youssef D, Khunti K, Davies M. Efficacy and safety of sodium-glucose cotransporter-2 inhibitors in type 2 diabetes mellitus: systematic review and network meta-analysis. Diabetes Obes Metab. 2016;18(8):783-94.

24. Johnston R, Uthman O, Cummins E, et al. Canagliflozin, dapagliflozin and empagliflozin monotherapy for treating type 2 diabetes: systematic review and economic evaluation. Health Technol Assess. 2017;21(2):1-218.

25. Hadjadj S, Rosenstock J, Meinicke T, Woerle HJ, Broedl UC. Initial combination of empagliflozin and metformin in patients with type 2 diabetes. Diabetes Care. 2016;39(10):1718-28.

26. Lewin A, DeFronzo RA, Patel S, et al. Initial combination of empagliflozin and linagliptin in subjects with type 2 diabetes. Diabetes Care. 2015;38(3):394-402.

27. Rosenstock J, Chuck L, González-Ortiz M, et al. Initial combination therapy with canagliflozin plus metformin versus each component as monotherapy for drug-naïve type 2 diabetes. Diabetes Care. 2016;39(3):353-62.

28. Merck \& Co Inc., Pfizer Inc. Clinical study report 005: A phase 3, randomized, double-blind, multicenter study to evaluate the efficacy and safety of the combination of ertugliflozin (MK-8835/PF04971729) with sitagliptin compared with ertugliflozin alone and sitagliptin alone, in the treatment of subjects with T2DM with inadequate glycemic control on metformin monotherapy (VERTIS FACTORIAL). Clinical study report 005: VERTIS FACTORIAL. Merck \& Co Inc./Pfizer Inc., New York/ New York. 2016.

29. DeFronzo RA, Lewin A, Patel S, et al. Combination of empagliflozin and linagliptin as second-line therapy in subjects with type 2 diabetes inadequately controlled on metformin. Diabetes Care. 2015;38(3):384-93.

30. Bailey TS, Takacs R, Tinahones FJ, et al. Efficacy and safety of switching from sitagliptin to liraglutide in subjects with type 2 diabetes (LIRA-SWITCH): a randomized, double-blind, double-dummy, active- 
controlled 26-week trial. Diabetes Obes Metab. 2016;18(12):1191-8.

31. Inagaki N, Kondo $\mathrm{K}$, Yoshinari $\mathrm{T}$, Takahashi $\mathrm{N}$, Susuta Y, Kuki H. Efficacy and safety of canagliflozin monotherapy in Japanese patients with type 2 diabetes inadequately controlled with diet and exercise: a 24-week, randomized, double-blind, placebo-controlled, phase III study. Expert Opin Pharmacother. 2014;15(11):1501-15.

32. Ji L, Ma J, Li H, et al. Dapagliflozin as monotherapy in drug-naive Asian patients with type 2 diabetes mellitus: a randomized, blinded, prospective phase III study. Clin Ther. 2014;36(1):84-100.

33. Stenlöf K, Cefalu W, Kim KA, et al. Efficacy and safety of canagliflozin monotherapy in subjects with type 2 diabetes mellitus inadequately controlled with diet and exercise. Diabetes Obes Metab. 2013;15(4):372-82.

34. Yang W, Han P, Min KW, et al. Efficacy and safety of dapagliflozin in Asian patients with type 2 diabetes after metformin failure: a randomized controlled trial. J Diabetes. 2016;8(6):796-808.

35. Rodbard H, Seufert J, Aggarwal N, et al. Efficacy and safety of titrated canagliflozin in patients with type 2 diabetes mellitus inadequately controlled on metformin and sitagliptin. Diabetes Obes Metab. 2016;18(8):812-9.

36. US Food and Drug Administration. STEGLATRO ${ }^{\mathrm{TM}}$ (ertugliflozin) prescribing information. 2017, p 11. https://www.accessdata.fda.gov/drugsatfda_docs/ nda/2017/209803Orig1s000lbl.pdf. Accessed 5 Nov 2018.

37. European Medicines Agency. Forxiga summary of product information. 2018, p 47. https://www.ema. europa.eu/documents/assessment-report/forxiga-eparpublic-assessment-report_en.pdf. Accessed 5 Nov 2018.

38. Zinman B, Wanner C, Lachin JM, et al. Empagliflozin, cardiovascular outcomes, and mortality in type 2 diabetes. N Engl J Med. 2015;373(22): 2117-28.

39. Neal B, Perkovic V, Mahaffey KW, et al. Canagliflozin and cardiovascular and renal events in type 2 diabetes. N Engl J Med. 2017;377(7):644-57.

40. Wiviott SD, Raz I, Bonaca MP, et al. Dapagliflozin and cardiovascular outcomes in type 2 diabetes. New Engl J Med. 2018. https://www.nejm.org/doi/ full/10.1056/NEJMoa1812389. Accessed 18 Jan 2018.

41. Cannon CP, McGuire DK, Pratley R, et al. Design and baseline characteristics of the eValuation of
ERTugliflozin effIcacy and safety CardioVascular outcomes trial (VERTIS-CV). Am Heart J. 2018;206:11-23.

42. Bailey C, Iqbal N, T'joen C, List J. Dapagliflozin monotherapy in drug-naïve patients with diabetes: a randomized-controlled trial of low-dose range. Diabetes Obes Metab. 2012;14(10):951-9.

43. Ferrannini E, Ramos SJ, Salsali A, Tang W, List JF. Dapagliflozin monotherapy in type 2 diabetic patients with inadequate glycemic control by diet and exercise a randomized, double-blind, placebocontrolled, phase 3 trial. Diabetes Care. 2010;33(10):2217-24.

44. Roden M, Weng J, Eilbracht J, et al. Empagliflozin monotherapy with sitagliptin as an active comparator in patients with type 2 diabetes: a randomised, double-blind, placebo-controlled, phase 3 trial. Lancet Diabetes Endocrinol. 2013;1(3):208-19.

45. Merck \& Co Inc., Pfizer Inc. Clinical study report 003: a phase 3, randomized, double-blind, placebocontrolled, 26-week multicenter study with a 26-week extension to evaluate the efficacy and safety of ertugliflozin monotherapy in the treatment of subjects with type 2 diabetes mellitus and inadequate glycemic control despite diet and exercise (VERTIS MET). Clinical study report 003: VERTIS MET. Merck \& Co Inc./Pfizer Inc., New York/ New York. 2016.

46. Bailey CJ, Gross JL, Pieters A, Bastien A, List JF. Effect of dapagliflozin in patients with type 2 diabetes who have inadequate glycaemic control with metformin: a randomised, double-blind, placebocontrolled trial. Lancet. 2010;375(9733):2223-33.

47. Häring H-U, Merker L, Seewaldt-Becker E, et al. Empagliflozin as add-on to metformin in patients with type 2 diabetes: a 24-week, randomized, double-blind, placebo-controlled trial. Diabetes Care. 2014;37(6):1650-9.

48. Lavalle-González F, Januszewicz A, Davidson J, et al. Efficacy and safety of canagliflozin compared with placebo and sitagliptin in patients with type 2 diabetes on background metformin monotherapy: a randomised trial. Diabetologia. 2013;56(12):2582-92.

49. Merck \& Co Inc., Pfizer Inc. Clinical study report 007: a phase 3, randomized, double-blind, placebocontrolled, 26-week multicenter study with a 78-week extension to evaluate the efficacy and safety of ertugliflozin in subjects with type 2 diabetes mellitus and inadequate glycemic control on metformin monotherapy (VERTIS MET). Clinical study report 007: VERTIS MET. Merck \& Co Inc./ Pfizer Inc., New York/New York. 2016. 
50. Jabbour S, Hardy E, Sugg J, Parikh S. Dapagliflozin is effective as add-on therapy to sitagliptin with or without metformin: a 24-week, multicenter, randomized, double-blind, placebo-controlled study. Diabetes Care. 2014;37(3):740-50.

51. Mathieu C, Ranetti AE, Li D, et al. Randomized, double-blind, phase 3 trial of triple therapy with dapagliflozin add-on to saxagliptin plus metformin in type 2 diabetes. Diabetes Care. 2015;38(11): 2009-17.

52. Søfteland E, Meier JJ, Vangen B, Toorawa R, Maldonado-Lutomirsky M, Broedl UC. Empagliflozin as add-on therapy in patients with type 2 diabetes inadequately controlled with linagliptin and metformin: a 24-week randomized, double-blind, parallel-group trial. Diabetes Care. 2017;40(2):201-9.

53. Merck \& Co Inc., Pfizer Inc. Clinical study report 006: a phase III, multicenter, randomized, doubleblind, placebo-controlled, parallel-group clinical trial to evaluate the safety and efficacy of ertugliflozin (MK-8835/PF-04971729) in the treatment of subjects with type 2 diabetes mellitus who have inadequate glycemic control on metformin and sitagliptin (VERTIS SITA2). Clinical study report 006: VERTIS SITA2. Merck \& Co Inc./Pfizer Inc., New York/New York.2016. 